Utah State University

DigitalCommons@USU

Ecology Center Publications

Ecology Center

$1-20-2020$

\title{
Ecological Response to Altered Rainfall Differs Across the Neotropics
}

\author{
Diane S. Srivastava \\ University of British Columbia \\ Régis Céréghino \\ Université de Toulouse \\ M. Kurtis Trzcinski \\ Université de Toulouse
}

\section{A. Andrew M. MacDonald \\ University of British Columbia}

Nicholas A. C. Marino

Universidade Federal do Rio de Janeiro

Dimaris Acosta Mercado

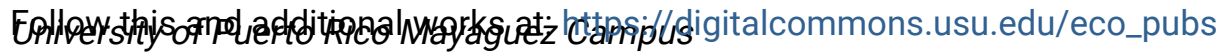

Part of the Ecology and Evolutionary Biology Commons

See next page for additionai authors

\section{Recommended Citation}

Srivastava, D. S., Céréghino, R., Trzcinski, M. K., MacDonald, A. A. M., Marino, N. A. C., Mercado, D. A., Leroy, C., Corbara, B., Romero, G. Q., Farjalla, V. F., Barberis, I. M., Dézerald, O., Hammill, E., Atwood, T. B., Piccoli, G. C. O., Bautista, F. O., Carrias, J.-F., Leal, J. S., Montero, G., Antiqueira, P. A. P., Freire, R., Realpe, E., Amundrud, S. L., de Omena, P. M., and Campos, A. B. A.. 2020. Ecological response to altered rainfall differs across the Neotropics. Ecology 101(4):e02984. 10.1002/ecy.2984

This Article is brought to you for free and open access by the Ecology Center at DigitalCommons@USU. It has been accepted for inclusion in Ecology Center Publications by an authorized administrator of DigitalCommons@USU.

For more information, please contact

digitalcommons@usu.edu.

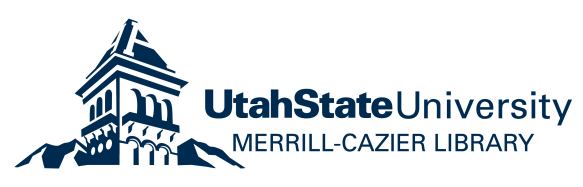




\section{Authors}

Diane S. Srivastava, Régis Céréghino, M. Kurtis Trzcinski, A. Andrew M. MacDonald, Nicholas A. C. Marino, Dimaris Acosta Mercado, Céline Leroy, Bruno Corbara, Gustavo Q. Romero, Vinicius F. Farjalla, Ignacio M. Barberis, Olivier Dézerald, Edd Hammill, Trisha B. Atwood, Gustavo C. O. Piccoli, and et al. 


\section{Ecological response to altered rainfall differs across the Neotropics}

Diane S. Srivastava (iD) 1,18 Régis Céréghino (iD) 2 M. Kurtis Trzcinski (iD 2 A. Andrew M. MacDonald iD 1,2 Nicholas A. C. Marino, ${ }^{3,4}$ Dimaris Acosta Mercado id ${ }^{5}$ Céline Leroy id ${ }^{6,7}$ Bruno Corbara (iD) 8 Gustavo Q. Romero id ${ }^{9}$ Vinicius F. Farjalla id ${ }^{3}$ Ignacio M. Barberis (id) ${ }^{10}$ Olivier Dézerald id, 7,11,12 EdD Hammill (id 1,13 Trisha B. Atwood (id ${ }^{13,14}$ Gustavo C. O. Piccoli, ${ }^{15}$ Fabiola Ospina-Bautista (iD), ${ }^{16,17}$ JeanFrançois Carrias id ${ }^{8}$ Juliana S. Leal, ${ }^{3}$ Guillermo Montero (iD) 10 Pablo A. P. Antiqueira id $9{ }^{9}$ Rodrigo Freire (iD ${ }^{10}$ Emilio Realpe, ${ }^{16}$ Sarah L. Amundrud id ${ }^{1}$ Paula M.deOmena, ${ }^{9}$ and Alice B. A. Campos ${ }^{3}$

${ }^{1}$ Departmetn of Zoology and Biodiversity Research Centre, University of British Columbia, Vancouver, British Columbia V6T $1 Z 4$ Canada

${ }^{2}$ Ecolab, Laboratoire Ecologie Fonctionnelle et Environnement, CNRS, UPS, INPT, Université de Toulouse, Toulouse 21941-901 France

${ }^{3}$ Departamento de Ecologia, Instituto de Biologia, Centro de Ciências da Saúde, Universidade Federal do Rio de Janeiro, Ilha do Fundão, 68020 Rio de Janeiro, RJ, Brazil

${ }^{4}$ Programa de Pós-Graduação em Ecologia, Universidade Federal do Rio de Janeiro, Ilha do Fundão, 68020 Rio de Janeiro, RJ, Brazil ${ }^{5}$ Department of Biology, University of Puerto Rico Mayaguez Campus, Mayaguez, 00681 Puerto Rico, USA ${ }^{6}$ AMAP, IRD, CIRAD, CNRS, INRA, Université Montpellier, Montpellier CEDEX-5, 34095 France

${ }^{7}$ ECOFOG (AgroParisTech, CIRAD, CNRS, INRA, Université de Guyane, Université des Antilles), 97379 Kourou, France ${ }^{8}$ CNRS, LMGE (Laboratoire Microorganismes: Génome et Environnement), Université Clermont-Auvergne, F-63000 ClermontFerrand, France

${ }^{9}$ Laboratory of Multitrophic Interactions and Biodiversity, Department of Animal Biology, Institute of Biology, University of Campinas (UNICAMP), 13083-862 Campinas, SP, Brazil

${ }^{10}$ Facultad de Ciencias Agrarias, Instituto de Investigaciones en Ciencias Agrarias de Rosario, IICAR-CONICET-UNR, Universidad Nacional de Rosario, S2125ZAA Zavalla, Argentina

${ }^{11}$ Laboratoire Interdisciplinaire des Environnements Continentaux (LIEC)-CNRS UMR 7360, Université de Lorraine, Campus Bridoux, 57070 Metz, France

${ }^{12}$ INRA, Agrocampus-Ouest, Ecology and Ecosystem Health, 65 rue de Saint-Brieuc, F-35042 Rennes, France

${ }^{13}$ Department of Watershed Sciences and the Ecology Center, Utah State University, Logan 84322 USA

${ }^{14}$ Department of Forest and Conservation Sciences, University of British Columbia, Vancouver, British Columbia V6T $1 Z 4$ Canada

${ }^{15}$ Department of Zoology and Botany, University of São Paulo State (UNESP/IBILCE), 15054 - 000 São José do Rio Preto, SP, Brazil

${ }^{16}$ Department of Biological Sciences, Andes University, Bogotá 111711 Colombia ${ }^{17}$ Departamento de Ciencias Biológicas, Universidad de Caldas, Caldas 170001 Colombia

Citation: Srivastava, D. S., R. Céréghino, M. K. Trzcinski, A. A. M. MacDonald, N. A. C. Marino, D. A. Mercado, C. Leroy, B. Corbara, G. Q. Romero, V. F. Farjalla, I. M. Barberis, O. Dézerald, E. Hammill, T. B. Atwood, G. C. O. Piccoli, F. O. Bautista, J.-F. Carrias, J. S. Leal, G. Montero, P. A. P. Antiqueira, R. Freire, E. Realpe, S. L. Amundrud, P. M. de Omena, and A. B. A. Campos. 2020. Ecological response to altered rainfall differs across the Neotropics. Ecology 00(00):e02984. 10.1002/ecy.2984

Abstract. There is growing recognition that ecosystems may be more impacted by infrequent extreme climatic events than by changes in mean climatic conditions. This has led to calls for experiments that explore the sensitivity of ecosystems over broad ranges of climatic parameter space. However, because such response surface experiments have so far been limited in geographic and biological scope, it is not clear if differences between studies reflect geographic location or the ecosystem component considered. In this study, we manipulated rainfall entering tank bromeliads in seven sites across the Neotropics, and characterized the response of the aquatic ecosystem in terms of invertebrate functional composition, biological stocks (total invertebrate biomass, bacterial density) and ecosystem fluxes (decomposition, carbon, nitrogen). Of these response types, invertebrate functional composition was the most sensitive, even though, in some sites, the species pool had a high proportion of drought-tolerant families. Total invertebrate biomass was universally insensitive to rainfall change because of statistical averaging of divergent responses between functional groups. The response of invertebrate functional composition to rain differed between geographical locations because (1) the effect of rainfall on bromeliad hydrology differed between sites, and invertebrates directly experience hydrology not rainfall and (2) the taxonomic composition of some functional groups differed between sites, and families differed in their response to bromeliad hydrology. These

Manuscript received 6 May 2019; revised 17 October 2019; accepted 12 November 2019. Corresponding Editor: Sharon P. Lawler.

${ }^{18}$ E-mail: srivast@zoology.ubc.ca 
findings suggest that it will be difficult to establish thresholds of "safe ecosystem functioning" when ecosystem components differ in their sensitivity to climatic variables, and such thresholds may not be broadly applicable over geographic space. In particular, ecological forecast horizons for climate change may be spatially restricted in systems where habitat properties mediate climatic impacts, and those, like the tropics, with high spatial turnover in species composition.

Key words: contingency; distributed experiment; freshwater; global change biology; macroinvertebrates; phytotelmata; precipitation.

\section{INTRODUCTION}

A large number of experiments have now shown that changes in climatic conditions have the potential to alter the structure and function of ecosystems. However, such experiments have generally been limited in at least one of three ways. First, most experiments focus on a single site. However, differences between sites in environmental conditions and species pools can create strong site contingencies in ecosystem dynamics (Lawton 1999). Our ability to forecast the future ecological effects of climate change over geographic scales may therefore remain limited (Pilkey and Pilkey-Jarvis 2007, Boeck et al. 2015, Planque 2016). Second, a focus on changes in mean conditions (Thompson et al. 2013) ignores the growing recognition that ecosystems can be dramatically changed by infrequent but extreme climatic events (Vasseur et al. 2014). It has been argued that research should instead explore the response of ecosystems to a broad range of climatic parameter space, in order to understand how sensitive the system is to deviations from mean conditions (Beier et al. 2012, Thompson et al. 2013, Kayler et al. 2015, Knapp et al. 2015). A complicating factor is that this sensitivity may differ between components of the system, such as species composition, biological stocks (i.e., biomass and densities of organisms) and ecosystem fluxes of energy and elements (Kayler et al. 2015). Third, although the majority of climate change studies have focused on temperature, changes in precipitation are expected to also be substantial but unpredictable, particularly in the Neotropics (Stocker 2014). Yet, there have been only a few studies examining how precipitation change can affect Neotropical ecosystems (Beier et al. 2012) and next to none on freshwater ecosystems (Pires et al. 2016, Marino et al. 2017).

Here we address all three of these limitations with a geographically replicated experiment that examines the sensitivity of a widespread Neotropical ecosystem to a broad range of precipitation parameter space. In doing so, we answer recent calls for geographic replication of precipitation change experiments using standardized protocols (Beier et al. 2012, Knapp et al. 2017). Climate models predict high regional variation in future precipitation, increasing droughts in some Neotropical areas but flooding in others (Duffy et al. 2015), but the precise geographic location of these changes is uncertain (Chadwick et al. 2016). We therefore focus our experiments on the ecological response to broad gradients in precipitation parameter space.
In seven sites in Central and South America (Fig. 1a), we used a coordinated experiment to compare the response of a freshwater ecosystem to the same proportional changes in precipitation. Since our focus here is on testing geographic generality, we examined the response of a single type of ecosystem, the aquatic food web in tank bromeliads, but in different geographic locations. Tank bromeliads (Fig. 1b) capture water and detritus, providing habitat for an aquatic food web composed largely of macroinvertebrates, especially insect larvae, and microorganisms. These food webs are easily manipulated and replicated and have been extensively studied (Petermann et al. 2015, Romero et al. 2016), making them an excellent candidate ecosystem for coordinated experiments. Moreover, because of their high abundance, bromeliads are important ecologically in Neotropical landscapes, accounting for much of the standing freshwater in forests and contributing substantially to litter decomposition, methane emission and the production of insect biomass (Goffredi et al. 2011, LeCraw et al. 2014, Dézerald et al. 2017).

We ask two related questions: (1) Which components of the ecosystem are most sensitive to rainfall change: the functional composition of communities, biological stocks, or ecosystem fluxes? And (2) are the ecological responses to rainfall change consistent across geographic space? The relative sensitivity of composition, stocks and ecosystem fluxes to rainfall change will depend both on the relationship between these ecological components, as well as the relative strength of buffering mechanisms particular to each component. The functional composition of ecological communities is often considered to be a major determinant of the ecological functions performed by these communities, suggesting that the effects of rainfall on functional composition will indirectly affect ecosystem stocks and fluxes (Pecl et al. 2017, Aspin et al. 2018). Such indirect effects on ecosystem stocks and fluxes can be large if a keystone functional group is lost (e.g., a facilitator), or minimal if there is a compensatory shift between functional groups with equivalent net impacts on an ecosystem response (e.g., different predation strategies that are equally effective in causing prey mortality). However, rainfall can also have direct effects on biological stocks and ecosystem fluxes, for example changing the volume of aquatic habitat or rates of nutrient leaching. If such direct effects of rainfall eclipse the indirect effects, then ecosystem stocks and fluxes may actually be more sensitive than functional composition to rainfall change (Srivastava 
a

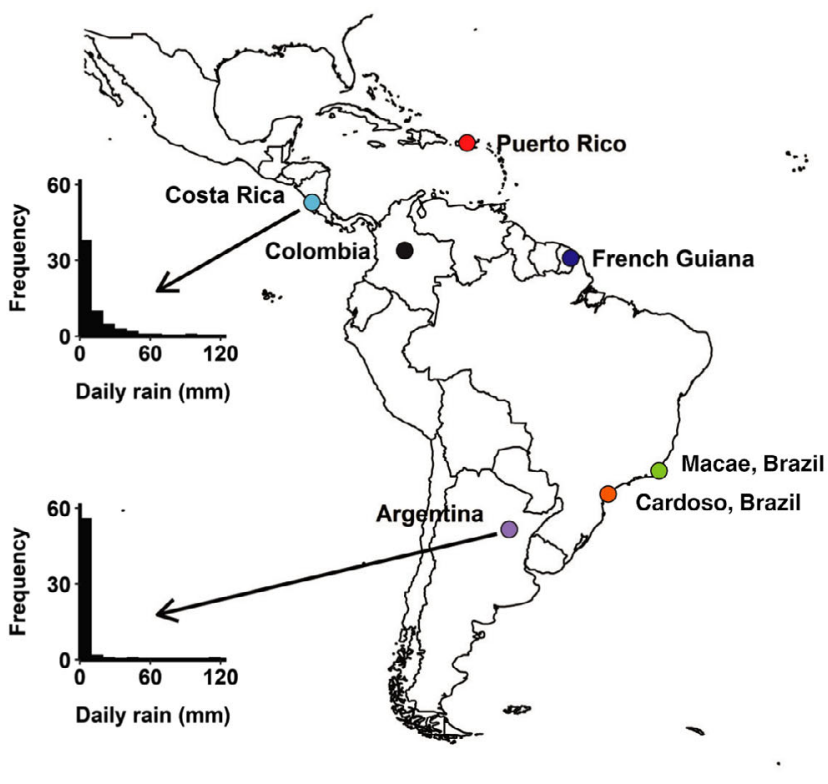

b

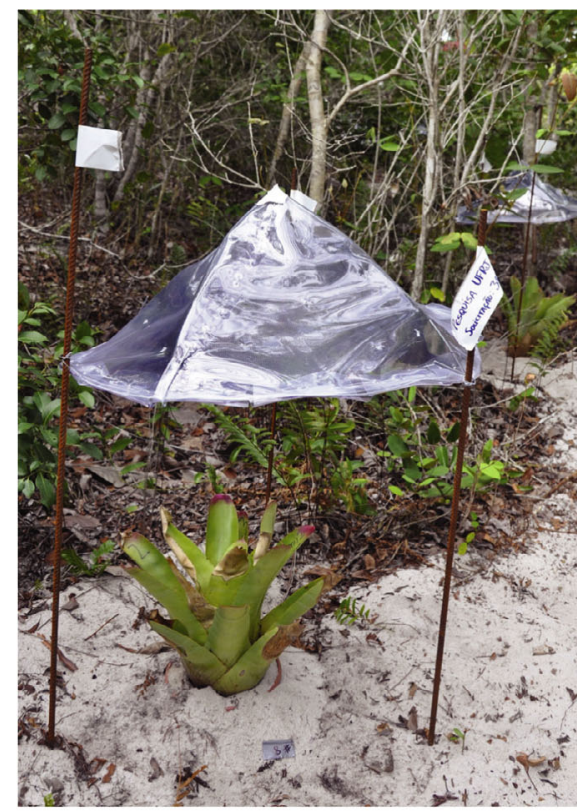

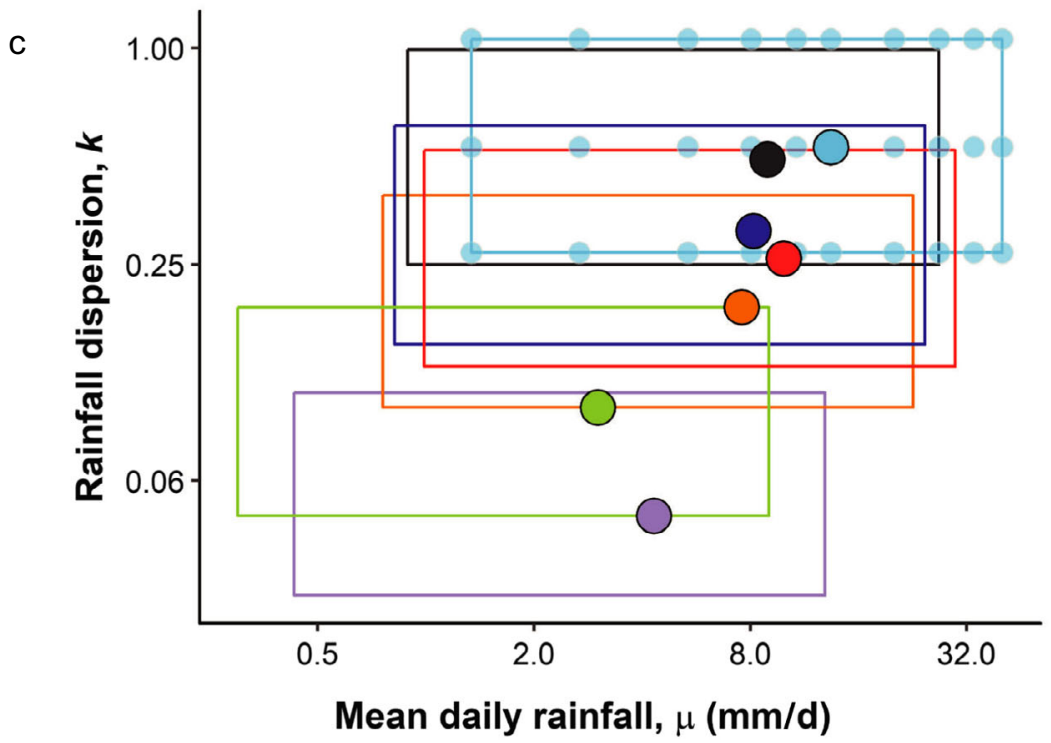

FIG. 1. (a) Rainfall manipulations were replicated at seven Neotropical sites that encompassed the natural range of tank bromeliads. Inset histograms show the frequency of daily rainfall under ambient conditions, for a 60-d period at two sites (top, Costa Rica; bottom, Argentina). (b) A tank-forming bromeliad, Neoregelia cruenta, in Macae, Brazil is sheltered from natural rainfall, permitting manual addition of water on an experimental schedule. (c) We manipulated two parameters of the rainfall frequency distribution: the mean daily amount of rainfall $(\mu)$ and the dispersion of rainfall amounts $(k)$. At each site, 30 rainfall manipulations (faded dots, shown for Costa Rica only, range denoted by rectangles for all sites) systematically covered the parameter space around each site-specific ambient condition (solid dots).

and Vellend 2005). The quantity and temporal distribution of rainfall can determine hydrological or desiccation stress on organisms, but the ecosystem effects of this stress may be buffered, and the strength of this buffering may differ between ecosystem components. Functional composition can be buffered from rainfall-related stress when species within functional groups differ in their sensitivity to the stressor and so compensate for each other. Asynchronous responses of species to stressors can also reduce the net effect on total stocks of organisms simply through the averaging of variation, often referred to as a portfolio effect (Doak et al. 1998). Finally, even when organisms responsible for an ecosystem flux are reduced by a stressor, the flux may be 
maintained if a different group of organisms or processes becomes important (Yachi and Loreau 1999). In bromeliads, aquatic decomposition rates can be maintained despite increases in hydroperiod length, because effects of reduced bacterial density on decomposition are offset by increases in both fungal activity and physiochemical leaching (Pérez et al. 2018).

Divergent predictions can also be made about the generality of ecological responses to rainfall change across geographic space. General responses may arise, for example, if organisms are selected to perform optimally under current conditions and therefore are always negatively affected when rainfall deviates from site-specific current conditions. On the other hand, contingent responses may arise because sites differ in the identity of species carrying out particular ecosystem functions (Lawton 1999, Trzcinski et al. 2016). If such species also differ in their sensitivity to rainfall, we would expect site-specific effects of rainfall on the functional structure of food webs and associated ecosystem processes. Sites also differ in their recent exposure to climatic events, and so sensitive taxa may have already been filtered from species pools of certain sites. This reduces the scope for species composition to respond to future climate change in these sites. Finally, site contingency may also arise if sites differ in how rainfall affects the abiotic environment, when the abiotic environment directly determines the performance of organisms. In the case of bromeliads, there is geographic variation in bromeliad morphology, canopy interception and evaporation potential, all of which influence either the capture or retention of rainwater in bromeliad tanks (Zotz and Thomas 1999), potentially leading to site-specific effects of rainfall on hydrology (Trzcinski et al. 2016). Bromeliad hydrology directly impacts organismal survival (Amundrud and Srivastava 2015), and can further influence water temperature and chemistry, as larger water volumes have more thermal inertia and greater chemical dilution.

\section{Methods}

\section{Selection of study sites and bromeliads}

Our goal was to manipulate precipitation in as many countries and habitats as possible, to determine whether results of experiments could be extrapolated across geographic space. We selected seven sites located in six different countries covering the range of tank-forming Bromeliaceae. Each site represented a unique habitat type (Appendix S1: Table S1) based on Holdridge Lifezone classification (Holdridge 1947).

No tank-forming genus of bromeliads occurred in all sites, so in each site, we selected the most abundant species with crateriform rosettes (Mori et al. 1997; Appendix S1: Table S1). Bromeliad size strongly affects invertebrate diversity (Srivastava et al. 2008, Amundrud and Srivastava 2015, Petermann et al. 2015), so we chose 30 bromeliads of similar capacity within each site
(Appendix S1: Table S1). We did not attempt to standardize bromeliad capacity across sites, because doing so would result in unrealistic predictions for each site: the size distribution of bromeliads naturally differs over geographic space, and such differences may be important mediators of site differences in the expected effects of rainfall change. For example, smaller bromeliads may dry or overflow more often than large bromeliads (Zotz and Thomas 1999). There is a trade-off when doing a multisite experiment between standardization (maximizes ability to detect a common mechanism) and realism (maximizes ability to predict outcome of a stressor). We leant towards the latter, as we were interested in whether knowing the effects of rainfall change at one site might allow us to predict the effects at another site.

\section{Experimental design}

As climate change affects individual sites relative to current conditions, our manipulations of precipitation were intentionally proportional to current site conditions and maintained the temporal autocorrelation structure of each site. In each site, we used recent meteorological data to characterize rainfall during the two months of the year when bromeliads contain most invertebrates (Appendix S1: Section S1). In our sites, the frequency distribution of days with a certain rainfall amounts (in 1-mm bins) is well described by a negative binomial distribution, whose two parameters, $\mu$ and $k$, describe, respectively, the mean daily amount of rainfall and the dispersion of rainfall events around this mean. For example, our Argentina site had many dry days, resulting in low $\mu$, interspersed with a few exceptionally rainy days, resulting in low $k$ (Fig. 1a). Although rainfall data are often fit with a hurdle model combining binomial and gamma distributions, there is no single way to alter the mean and dispersion of rainfall in such models; by contrast, such alterations are simple in a negative binomial, and it was as good a fit to the rainfall data as a gamma-binomial hurdle model. We exposed bromeliads and their food webs to altered rainfall regimes representing up to a 30-fold change in $\mu$ (ambient $\mu$ multiplied by scalars: $0.1,0.2,0.4,0.6,0.8,1.0,1.5,2.0$, $2.5,3.0$ ) and up to a fourfold change in $k$ (ambient $k$ multiplied by scalars: $0.5,1.0,2.0)$ relative to current conditions, using a response surface design with 30 unique $\mu$ by $k$ combinations (Fig. 1c). As negative binomial distributions are discrete distributions, we rounded all rainfall amounts to integer values of milliliters. For each of these 30 negative binomial distributions, we calculated the number of days in each integer rainfall class for the $60-\mathrm{d}$ period of the experiment and ordered these daily rainfall events to match the rank order in the ambient scenario. This ensures that our experimental rainfall treatments differed in terms of $\mu$ and $k$ but were synchronous in the timing of rainfall events. Our manipulations exceeded recent annual variation in either $\mu$ or $k$ at each site (Appendix S2: Fig. S1). 


\section{Experimental schedule}

We ran our experiment for $65 \mathrm{~d}$, including one day of ecosystem assembly (Day 0), a day for abiotic and microbial measurements (Day 1), $60 \mathrm{~d}$ of water addition and depth measurements (Day 1-60), and a single day of median rainfall for each treatment (Day 61) to prepare the system for measurements of water, gas, and microbes (Day 62) and litter decomposition, nutrient uptake, and aquatic invertebrates (Day 64). The two-month duration of experiments was enough time for litter decomposition and invertebrate growth, but avoided entering the dry season when insects leave the bromeliad as terrestrial adults (Dézerald et al. 2017). As a maximum of 10 bromeliads could be sampled per day, we staggered the initiation of the experiment over three consecutive days. We found no statistical differences in our response variables between these three temporal blocks.

Assembly of bromeliad ecosystems (Day 0).- A week prior to the start of the experiment, we emptied all bromeliads of their contents, retained coarse $(>850 \mu \mathrm{m})$ and fine $(<850 \mu \mathrm{m})$ detritus and sorted macroinvertebrates into species groups. We measured bromeliad capacity and, using digital image analysis, potential catchment area (surface leaf area that drains towards center, as opposed to leaf tips).

On Day 0, we evenly divided the fine and coarse detritus between the 30 bromeliads and stocked each bromeliad with the same community in terms of invertebrate families and functional groups. We added two rehydrated leaf packs to measure litter decomposition. Litter species (Appendix S1: Table S2) were chosen that were locally abundant and rapidly consumed by bromeliad detritivores (as assessed by feeding trials). We chose not to use a standard litter species, because such a species would be non-native to many sites (no tree species occurred in all sites). We prepared leaf packs by cutting two or three senescent leaves into strips, avoiding the primary venation. We dried the litter strips and determined their dry mass. Rehydrated leaf packs were sewn together with a few stitches of monofilament along the primary venation. Finally, we programmed a temperature logger (Thermochron iButton $-40^{\circ} \mathrm{C}$ thru $85^{\circ} \mathrm{C}$, Maxim Integrated, San Jose, CA USA) to record hourly temperature, wrapped it in wax film, and submersed it in each bromeliad.

Manipulation of precipitation (Day 1-60).-We installed rain shelters ( $>3 \mathrm{~m}$ apart) over each potted bromeliad at the start of a 3-d pre-manipulation period (Day -2 to 0 ). During this pre-manipulation period, the median rainfall of the ambient treatment was added to each bromeliad on three consecutive days. This allowed the assembled bromeliad communities time to acclimate. All bromeliads ended with one extra day of rainfall, equal to the median for the particular rainfall treatment; this ensured that bromeliads contained enough water for water samples to be taken. To convert rainfall $(\mathrm{cm})$ into the volume of water $(\mathrm{mL})$ to be added to a bromeliad, we first adjusted incoming rainfall for deflection by the forest canopy and by bromeliad leaves (Appendix S1: Section S2) and then multiplied the adjusted rainfall (cm) by the mean catchment area $\left(\mathrm{cm}^{2}\right)$. We slowly added water to each plant with a narrow-mouthed watering can, dividing this water equally among leaf wells. Large volumes $(>1 \mathrm{~L})$ were added over the course of the day. Water for this experiment was either filtered natural rainfall, spring water, or bottled mineral water.

Hydrology measurements (Day 1-60).-Every one to two days, we measured water level $( \pm 1 \mathrm{~mm})$ in the central tank and two marked outer leaves. We calculated the following six hydrologic metrics following Marino et al. (2017): the proportion of days a bromeliad was dry, the proportion of days that a bromeliad overflowed, the coefficient of variation $(\mathrm{CV})$ in water depth over time, the mean water depth, the longest number of consecutive records without water, and the number of days since the bromeliad last contained water. These hydrologic variables were calculated per leaf and then averaged to the plant level.

Bromeliad uptake of detrital nitrogen (Day 30-60).-We fertilized daily a local species of shrub with $50 \mathrm{~mL}$ of ${ }^{15} \mathrm{~N}$ labeled ammonium sulfate solution $(5 \mathrm{~g} / \mathrm{L}$, 10 atom $\%{ }^{15} \mathrm{~N}$ ) for at least two weeks, then collected and dried leaves in an oven at $50-60^{\circ} \mathrm{C}$. Labeled leaves were rehydrated before adding to bromeliads at Day 30 . At the end of the experiment, we lightly washed new bromeliad leaves with distilled water prior to collection, dried them at $50^{\circ}-60^{\circ} \mathrm{C}$ and sent the dried leaves to Cornell University Stable Isotope Laboratory (Ithaca, New York, USA) for processing for ${ }^{15} \mathrm{~N}$ isotopic abundance $\left(\delta^{15} \mathrm{~N}\right)$, a proxy for bromeliad uptake of nitrogen from detritus.

Ecosystem, microbial, and water chemistry measurements (Day 1, 62).-We measured water chemistry and microbial densities at the beginning and end of the experiment. We sampled water for $\mathrm{CO}_{2}$ concentrations at dawn, when heterotrophic respiration (rather than plant photosynthesis and respiration) largely determines water $\mathrm{CO}_{2}$ concentrations (Atwood et al. 2014, Hammill et al. 2015). We sampled water with a 5-mL bevel-ended glass syringe, injected the water into a vacuum-sealed $3-\mathrm{mL}$ vial ensuring no headspace, and analyzed it for $\mathrm{CO}_{2}$ using gas chromatography within $72 \mathrm{~h}$ (Hudson 2004). Although $\mathrm{CO}_{2}$ concentration within bromeliad water is technically not a flux, because bromeliads within a site were similar in size and atmospheric conditions we follow Atwood et al. (2014) in assuming that differences in dissolved $\mathrm{CO}_{2}$ are proportional to differences in $\mathrm{CO}_{2}$ flux. We measured water turbidity, dissolved $\mathrm{O}_{2}$, and $\mathrm{pH}$ using hand-held data loggers. We pooled $>10 \mathrm{~mL}$ of water from 10 leaves of each bromeliad, $9 \mathrm{~mL}$ of which 
was fixed with $1 \mathrm{~mL}$ of a sodium borate-saturated formalin solution to preserve bacteria. Bacteria counts in each sample were determined in the laboratory either through epifluorescence microscopy after DAPI (40,6diamidino-2-phenylindole) staining following methods in Marino et al. (2017), or, in the case of French Guiana and Puerto Rico only, by using flow cytometry after staining with SYBR Green I following methods in Brouard et al. (2011). This difference in method was necessitated by differences in the equipment available to each research team, and a previous study suggests that the two methods yield comparable results (Monfort and Baleux 1992).

At Day 60, we removed leaf packs from each bromeliad, lightly rinsed them to remove invertebrates (recorded), and dried the litter at $50-60^{\circ} \mathrm{C}$. We approximated litter decomposition as the percentage of mass lost over the experiment. We measured the final water volume in each bromeliad and retrieved temperature loggers.

Invertebrate measurements (Day 64).-We collected all macroinvertebrates from each bromeliad by searching detritus and rinse water following plant dissection. We recorded body lengths of all species and converted these to biomass using mass-length allometric relationships (Bromeliad Working Group, unpublished manuscript). Invertebrates were preserved in $70 \%$ ethanol and identified to species or morphospecies. Species were assigned to functional feeding groups based on the literature and field observation.

\section{Statistical analysis}

Univariate responses to rainfall and hydrological change.-We evaluated the response of invertebrate functional group biomass, biological stocks and ecosystem fluxes, fitting our data to three different sets of candidate models: (1) based on rainfall, (2) based on hydrology and temperature, or (3) competing the best rainfall and hydrology models. All models included the covariate of log-transformed bromeliad capacity, known to be a strong predictor of invertebrate communities and ecosystem processes (Petermann et al. 2015, Romero et al. 2016), and a main fixed effect of site to account for differences in ambient conditions. Although we could have built mixed effect models with either site, or rainfall slopes associated with site, as a random effect, this would not have allowed us to quantify the magnitude of contingency (i.e., the site $\times$ rainfall interactions), nor interpret such site contingency in terms of site characteristics. The candidate set of rainfall models represented all combinations of linear and quadratic terms of $\mu$ scalar and $k$ scalar, both with and without site interactions, as well as a null model with no rainfall terms (total of 17 candidate models). Quadratic terms allow for optima at current conditions, one of our initial predictions. The candidate set of hydrological models include the six hydrologic variables and the mean and $\mathrm{CV}$ of water temperature standardized for site, both with and without interactions for site (total of 17 candidate models including the null model). We did not include water $\mathrm{pH}$ as an explanatory variable in these models as, unlike hydrological and temperature variables, it did not respond to rainfall manipulations (Appendix S2: Table S2).

For each set of candidate models, we report the bestfit model (delta $\mathrm{AIC}_{\mathrm{c}}=0$; MuMIn $\mathrm{R}$ package) rather than averaging the top models, as we were primarily interested in comparing the amount of deviance explained by either rainfall or hydrology models, rather than in determining the relative importance of variables. We evaluated the significance of model variables using type 2 (no significant interactions) or type 3 (significant interactions) ANOVAs (R package car). We accepted the null model as the best model when there were no significant rainfall or hydrology variables in alternative topranked models (delta $\mathrm{AIC}_{\mathrm{c}}<2$ ). When the best-fit models included significant site $\mathrm{x}$ rainfall terms, we competed these models against equivalent models with $\mu$ and $k$ in original units rather than as scalars (i.e., proportional to site ambient conditions) and without site interactions; this comparison allowed us to determine if the site-specific response originated from subsampling a universal but nonlinear response. We calculated the deviance explained by either the rainfall or hydrology terms (including interactions) in the best-fit models, independent of the main effects of site and log bromeliad capacity and adjusting for the number of parameters ( $\mathrm{R}$ package modEvA). The ecosystem flux response variables were fit with Gaussian distributions, with the response variables transformed as needed. For the nitrogen uptake data, we used Tukey's Ladder of Powers as implemented in the rcompanion $\mathrm{R}$ package to obtain a range of power transformations that normalized the data (ShapiroWilks W>0.90) and chose a power transformation (eight root) that resulted in residuals being uncorrelated with fitted values. To use Tukey's Ladder of Powers, we needed to first ensure all values were positive by adding a constant of $4 \%$. For the biomass and density data, we used negative binomial distributions (estimates of theta first optimized with function glm.nb). Although the negative binomial distribution is based on discrete data, and biomass data are usually considered continuous, we found this distribution to be the best fit to the invertebrate biomass data. In our experiment, the biomass data had a surfeit of zeroes because it was influenced by processes that affected the number of component organisms (e.g., oviposition, drought mortality, predation mortality, emergence, loss through flushing), not only the size of each organism (somatic growth, interspecific differences). These discrete and continuous processes, in combination, resulted in a distribution that was well approximated by a negative binomial.

Models were unchanged when we relaxed the requirement to include $\log$ (bromeliad capacity) as a covariate. We 
excluded Cardoso from hydrology models as no water depths were measured in this site. Ecosystem flux variables were occasionally missing values from bromeliads, due to methodological issues; invertebrate functional groups sometimes had zero values representing the heterogeneous distribution of invertebrates. We excluded sites with less than 10 non-zero values for a given response variable to guard against spurious results caused by insufficient degrees of freedom (remainder of data missing) or information (remainder of biomass data zero; Appendix S1: Section S3). A few outliers were removed when detected (outlier.test in R package car), but this applied to $<1 \%$ of data.

Multivariate responses to rainfall and hydrological change.-We modeled the relative biomass of all six invertebrate functional groups (hereafter "functional composition") using canonical correspondence analysis (CCA; R package vegan). The predictors in the CCA model, tested by permutation, included the covariate of $\log ($ bromeliad capacity), main effects of site, and all combinations of log ( $\mu$ scalar), $\log (k$ scalar), and site, and all combinations of the absolute values of $\log (\mu$ scalar $)$ and $\log (k$ scalar $)$, and site (Appendix S2: Table S3). By using the absolute value of scalars, we can test for symmetrical changes in functional composition relative to ambient conditions; the absolute value of $\log (\mu$ scalar $)$ and $\log (k$ scalar $)$ is zero at ambient conditions $(\mu$ scalar $=1, k$ scalar $=1)$, and positive otherwise.

We used Mantel tests to test if pairwise differences between sites in their response to rainfall in terms of functional composition correlated with pairwise site differences in hydrological response to rainfall, family composition of their species pools, hydrological sensitivity of their species pools (Appendix S1: Section S4), geographic distance, and climate (annual mean temperature and annual precipitation (BIO1 and BIO12, respectively; data available online) ${ }^{19}$ To calculate differences between a pair of sites in either their functional or hydrologic response to rainfall, we used the effect size of the site $x$ rainfall interactions for each response within a two-site multivariate model (using the R function adonis::vegan, model terms identical to those in CCA). For other predictors, we calculated pairwise dissimilarity using Jaccard dissimilarity for biological variables and Euclidean distances for space and climate. Annual precipitation was square-root transformed to ensure a similar range to temperature, and species pool data were Hellinger transformed to downweight rare species.

\section{RESUlts}

\section{System components differ in sensitivity to rainfall and hydrology}

We measured the effects of altered rainfall, and resultant changes in hydrology, on invertebrate functional

\footnotetext{
${ }^{19} \mathrm{http} / / /$ www.worldclim.org
}

composition, biological stocks, and ecosystem fluxes. Rainfall alterations had the most effect on invertebrate functional composition, significantly affecting the biomass of five of six invertebrate functional groups and explaining up to $23 \%$ of the residual variation after accounting for site and bromeliad size (14\% after adjusting for number of variables: Fig2a). By contrast, alterations in rainfall had relatively minor effects on biological and ecosystem fluxes, significantly affecting only two of these five variables and explaining a maximum of $15 \%$ of the residual variation after accounting for main effects of site and bromeliad size $(5 \%$ after adjusting for the number of variables: Fig. 2a). Hydrological differences between bromeliads also affected invertebrate functional groups (up to $32 \%$ residual variation) more than biological stocks or ecosystem fluxes (maximum of $5 \%$ residual variation; Fig. 2b). Overall, the models explained a substantial amount of the variance in many response variables, especially ecosystem stocks and fluxes because of strong main effects of site (Table 1).

The significant response of invertebrate functional groups to rainfall contrasts with the insensitivity of total invertebrate biomass (the sum of all invertebrate functional groups) to rainfall (Fig. 2a, Table 1). We investigated whether this discrepancy is related to a portfolio effect, whereby functional groups differ in their response to rainfall and aggregating these disparate responses results in a statistical reduction in variation. As predicted by a portfolio effect, we found that there is no correlation between the biomasses of the different functional groups (mean $r=0.026,95 \% \mathrm{CI}=-0.012,0.064$, after accounting for bromeliad capacity and site; Appendix S2: Fig. S2). Other stocks and fluxes that were unaffected by rainfall change included litter decomposition and $\mathrm{CO}_{2}$ concentration (Fig. 2a, Table 1).

An alternative prediction was that invertebrate communities would have limited scope to respond to rainfall change if the species pool of drought prone sites contained a low proportion of drought-sensitive taxa. To investigate this possibility, we first calculated a hydrologic sensitivity index for each taxonomic family as the proportion of deviance explained by hydrologic variables over the entire data set (Appendix S1: Section S4). We then calculated the biomass-weighted average of this hydrologic sensitivity index for the species pool for each site. As we predicted, the hydrologic sensitivity of species pools is lower for sites whose bromeliads currently experience more drought $\left(r=-0.90, t_{4}=-4.22, P=0.013\right.$; Fig. 3). We investigate in the next section whether such differences between sites in their species pool explain differences in their sensitivity to rainfall change.

\section{Geographic locations differ in sensitivity to rainfall and hydrology}

Ecological responses to rainfall change were rarely consistent across sites. Only bacterial density and 

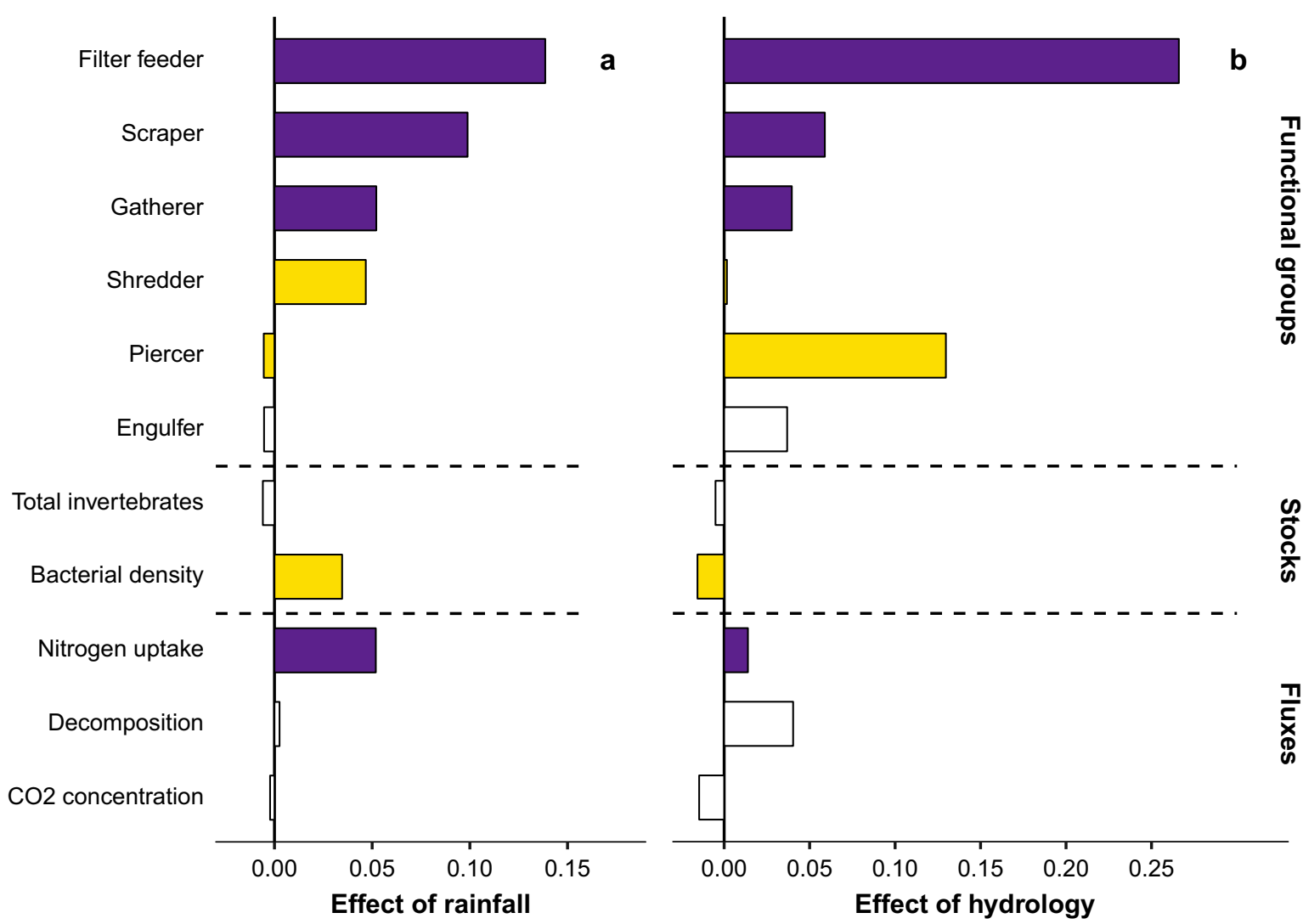

FIG. 2. The effect of (a) rainfall and (b) hydrology on the bromeliad ecosystem, including the biomass of invertebrate functional groups, organismal stocks, and elemental fluxes. Effect sizes are represented by the amount of residual deviance explained by either rainfall or hydrology terms, after accounting for covariates and after adjustment for the number of retained terms in the best-fit model. Negative effects occur when very little deviance is explained by the best model. For each response variable, the best model was either contingent (purple, includes interactions between either rainfall or hydrology and site), general (yellow, has only additive effects of rainfall or hydrology and site), or null (white, no effect of rainfall or hydrology).

shredder biomass showed both a general and significant response to rainfall. Bacterial density universally decreased as the total amount of rainfall that entered bromeliads increased, suggesting dilution or flushing processes (Appendix S2: Fig. S3). Note that although there were differences between sites in the method used to determine bacterial density, such differences necessarily only contributed to site differences in mean densities $\left(\chi_{1}^{2}=153, P<0.0001\right)$, not within-site effects of total rainfall (method $\times \mu$ scalar: $\chi_{1}^{2}=0.15, P=0.70$ ). Shredder biomass universally peaked at current rainfall dispersion, consistent with local adaptation to current conditions (Appendix S2: Fig. S3). By contrast, a number of response variables showed strong site contingency in their response to rainfall, especially nitrogen uptake by the bromeliad and biomasses of gatherer, scraper, and filter-feeder invertebrates (Fig. 2a). We also found large differences between sites in the response of multivariate functional composition of invertebrates to rainfall, here best represented as the absolute shift in rainfall dispersion from current conditions (Appendix S2: Fig. S7, Table S3).
There are several ways in which contingency might arise. First, contingency could be an artefact of each site sampling a small subset of a universal but nonlinear response to geographic gradients in rainfall, similar to the variety of relationships argued to originate from subsampling a unimodal diversity pattern over productivity gradients (Fraser et al. 2015). Indeed, detrital nitrogen uptake by bromeliad leaves showed a general unimodal relationship with regard to the realized value of $k$ (Appendix S2: Fig. S4), and such a model describes the data better than considering rainfall change relative to site ambient conditions (Table 1). However, we can discount a similar explanation for contingency in the remaining response variables, as a global model based on nonlinear responses to realized rainfall values always fit the data less well than the site-specific model based on relative changes in rainfall (Table 1).

Second, sites may differ in how rainfall affects the abiotic environment directly experienced by organisms. Indeed, our rainfall treatments affected key hydrological and thermal metrics, and the strength of many of these rainfall effects differed between sites (Fig. 2a, Table 1). 
TABLE 1. Effects of rainfall and hydrology on ecosystem responses of bromeliad communities as determined by an $\mathrm{AIC}_{\mathrm{c}}$ model selection procedure.

\begin{tabular}{|c|c|c|c|c|c|}
\hline $\begin{array}{l}\text { Response } \\
\text { variable }\end{array}$ & $\begin{array}{l}\text { Best relative } \\
\text { rainfall model }\end{array}$ & $\begin{array}{l}\text { Best hydrology } \\
\text { model }\end{array}$ & $\begin{array}{l}\text { Best of rainfall and } \\
\text { hydrology models }\end{array}$ & $\begin{array}{l}\text { Best absolute } \\
\text { rainfall model }\end{array}$ & $\begin{array}{l}\text { Best of relative and } \\
\text { absolute rainfall models }\end{array}$ \\
\hline $\begin{array}{c}\text { Filter feeder } \\
\text { biomass } \dagger\end{array}$ & $\begin{array}{l}\log (\text { capacity }+ \text { site }) \times \\
\log \left(\mu \text { scalar }^{2}+\log \right. \\
\left(\mu \text { scalar }^{2}\right)\end{array}$ & $\begin{array}{l}\log (\text { capacity }+ \text { site } \\
\text { CV water depth })\end{array}$ & $\begin{array}{l}\text { hydrology }[44 \%]: \\
\Delta \text { AIC }_{\mathrm{c}}=18.1\end{array}$ & $\begin{array}{l}\log (\text { capacity }+ \text { site })+ \\
\log \mu+\log \mu^{2}\end{array}$ & $\begin{array}{l}\text { relative }[42 \%]: \\
\Delta \Delta \mathrm{AIC}_{\mathrm{c}}=15.15\end{array}$ \\
\hline $\begin{array}{l}\text { Scraper } \\
\text { biomass: }\end{array}$ & $\begin{array}{l}\log (\text { capacity }+ \text { site }) \times \\
\log \left(k \text { scalar }^{2}+\log \right. \\
\left(k \text { scalar }^{2}\right)\end{array}$ & $\begin{array}{l}\log (\text { capacity }+ \text { site } \times \\
\text { proportion } \\
\text { days bromeliad dry })\end{array}$ & $\begin{array}{l}\text { hydrology }[49 \%]: \\
\Delta \mathrm{AIC}_{\mathrm{c}}=7.31\end{array}$ & $\begin{array}{l}\log (\text { capacity }+ \text { site })+ \\
\log k+\log k^{2}\end{array}$ & $\begin{array}{l}\text { relative }[60 \%]: \\
\Delta \mathrm{AIC}_{\mathrm{c}}=13.73\end{array}$ \\
\hline $\begin{array}{l}\text { Gatherer } \\
\text { biomass: }\end{array}$ & $\begin{array}{l}\log (\text { capacity }+ \text { site }) \times \\
\log \left(k \text { scalar }^{2}+\log \right. \\
\left(k \text { scalar }^{2}\right)\end{array}$ & $\begin{array}{c}\log (\text { capacity }+ \text { site } \\
\text { CV water depth })\end{array}$ & $\begin{array}{l}\text { rainfall }[58 \%]: \\
\Delta \text { AIC }_{\mathrm{c}}=20.4\end{array}$ & $\begin{array}{l}\log (\text { capacity }+ \text { site })+ \\
\log k+\log k^{2}\end{array}$ & $\begin{array}{l}\text { relative [58\%]: } \\
\qquad \Delta \mathrm{AIC}_{\mathrm{c}}=13.56\end{array}$ \\
\hline $\begin{array}{l}\text { Shredder } \\
\text { biomass }\end{array}$ & $\begin{array}{l}\log (\text { capacity }+ \text { site })+ \\
\log \left(k \text { scalar }^{2}+\log \right. \\
\left(k \text { scalar }^{2}\right)\end{array}$ & $\begin{array}{l}\log (\text { capacity }+ \text { site }+ \\
\text { proportion } \\
\text { days with overflow })\end{array}$ & $\begin{array}{l}\text { rainfall }[46 \%]: \\
\Delta \mathrm{AIC}_{\mathrm{c}}=2.76\end{array}$ & - & - \\
\hline $\begin{array}{l}\text { Piercer } \\
\text { biomass } \dagger\end{array}$ & $\begin{array}{l}\log (\text { capacity }+ \text { site })+ \\
\log (\mu \text { scalar })\end{array}$ & $\begin{array}{l}\log (\text { capacity }+ \text { site } \times \\
\text { proportion } \\
\text { days with overflow })\end{array}$ & $\begin{array}{l}\text { hydrology }[25 \%]: \\
\Delta \mathrm{AIC}_{\mathrm{c}}=8.85\end{array}$ & - & - \\
\hline $\begin{array}{l}\text { Engulfer } \\
\text { biomass }\end{array}$ & $\log ($ capacity + site $)$ & $\log ($ capacity + site $)$ & $\begin{array}{l}\text { neither [capacity } \\
\text { and site: } 36 \% \text { ] }\end{array}$ & - & - \\
\hline $\begin{array}{l}\text { Total } \\
\text { invertebrates }\end{array}$ & $\log ($ capacity + site $)$ & $\begin{array}{l}\log (\text { capacity }+ \text { site } \times \\
\text { proportion } \\
\text { days with overflow })\end{array}$ & $\begin{array}{l}\text { hydrology }[20 \%]: \\
\qquad \text { AIC }_{\mathrm{c}}=2.00\end{array}$ & - & - \\
\hline $\begin{array}{c}\text { Bacterial } \\
\text { density§ }\end{array}$ & $\begin{array}{l}\log (\text { capacity }+ \text { site })+ \\
\log \\
(\mu \text { scalar })\end{array}$ & $\log ($ capacity + site $)$ & $\begin{array}{l}\text { rainfall [63\%]: } \\
\qquad \Delta \mathrm{AIC}_{\mathrm{c}}=6.46\end{array}$ & - & - \\
\hline $\begin{array}{l}\text { Nitrogen } \\
\text { uptakeł, }\end{array}$ & $\begin{array}{l}\log (\text { capacity }+ \text { site } \times \\
\left(\log \left[k \mathrm{scalar}^{2}\right]+\log \right. \\
\left.\left[k \mathrm{scalar}^{2}\right]\right)\end{array}$ & $\begin{array}{l}\log (\text { capacity }+ \text { site } \times \\
\text { longest } \\
\text { dry period })\end{array}$ & $\begin{array}{l}\text { rainfall and } \\
\text { hydrology } \\
\text { similar [70\%]: } \\
\Delta \mathrm{AIC}_{\mathrm{c}}=1.42\end{array}$ & $\begin{array}{l}\log (\text { capacity }+ \text { site })+ \\
\log k+\log k^{2}\end{array}$ & $\begin{array}{l}\text { absolute }[67 \%]: \\
\Delta \text { AIC }_{\mathrm{c}}=8.07\end{array}$ \\
\hline $\begin{array}{l}\text { Litter } \\
\text { decomposition‡,\# }\end{array}$ & $\log ($ capacity + site $)$ & $\begin{array}{l}\log (\text { capacity }+ \text { site }+ \\
\text { cv water depth })\end{array}$ & $\begin{array}{l}\text { hydrology }[90 \%]: \\
\Delta \text { AIC }_{\mathrm{c}}=11.05\end{array}$ & - & - \\
\hline $\begin{array}{l}\mathrm{CO}_{2} \\
\text { concentration } \|\end{array}$ & $\log ($ capacity + site $)$ & $\log ($ capacity + site $)$ & $\begin{array}{c}\text { neither [capacity } \\
\text { and site: } 89 \% \text { ] }\end{array}$ & - & - \\
\hline
\end{tabular}

Notes: Relative rainfall models include proportional change in $\mu$ or $k$ relative to ambient conditions ( $\mu$ scalar and $k$ scalar, respectively), whereas hydrology models include six metrics of water depth dynamics and two metrics of temperature dynamics. Absolute rainfall models include $\mu$ or $k$ in their measured units, and were examined for the four response variables with significant site $\times$ relative rainfall interaction terms. We competed the top relative rainfall and hydrology models against each other ("neither" represents the case where neither model was $>2 \mathrm{AIC}_{\mathrm{c}}$ units better than a null model with just the covariates of bromeliad capacity and site). We similarly competed the top relative and absolute rainfall models. The adjusted deviance-squared for the best model is shown in square brackets, with the caution that AIC model selection is not based on this metric.

$\uparrow$ Colombia and Costa Rica excluded as $<10$ non-zero values.

$\$$ All sites included.

$\S$ Argentina and Colombia excluded as $<10$ non-zero values.

II Eighth root.

\# Log-transformed.

|| Square root, Cardoso, and Puerto Rico excluded as data was not collected at these sites.

We had predicted that organisms and ecosystem functions would be more strongly related to these hydrologic and thermal metrics than to rainfall since changes in these abiotic conditions mediate rainfall effects. Supporting this prediction, we found that hydrologic metrics in particular explained more variance than rainfall for a number of biological responses (Fig. 2b, Table 1, Appendix S2: Fig. S5). For example, filter feeder biomass (entirely composed of mosquitoes, see Appendix S2: Table S1) was better explained by temporal variability in water depth than by any rainfall variable. Moreover, site contingency accounted for only $15 \%$ of the total effect of water depth variation vs. $55 \%$ of the total effect of rainfall (Fig. 4a,b). Thus the site contingency in effects of rainfall on filter feeders may have been due, in part, to differences between sites in how rainfall translated into variability in water depth (Fig. 4c); for example, the site-specific effects of rainfall (site $\times$ quadratic effects of changed $\mu, \chi_{8}^{2}=34.9$, $P=0.00003$ ) were no longer significant once we added variability in water level to the model (site $\times$ quadratic effects of changed $\mu, \chi^{2}{ }_{6}=10.4, P=0.11$ ).

Finally, contingency can arise through taxonomic differences in the species found at each site. The sites in this study were $600-6,000 \mathrm{~km}$ apart, in habitats ranging from sand dunes to montane rainforests, and therefore their species pools have as few as $32 \%$ and as many as $80 \%$ of taxonomic families in common (Appendix S2: Table S1). We focused on families, as traits are often conserved at this level in aquatic insects (Poff et al. 2006) and most taxa were identified at least to family. Certain functional groups showed high levels of taxonomic turnover between sites (Appendix S2: Table S1). For example, piercing predators consisted entirely of Tabanidae in Argentina, but were dominated by Tanypodinae chironomids in Macae and predacious Ceratopogonidae in 


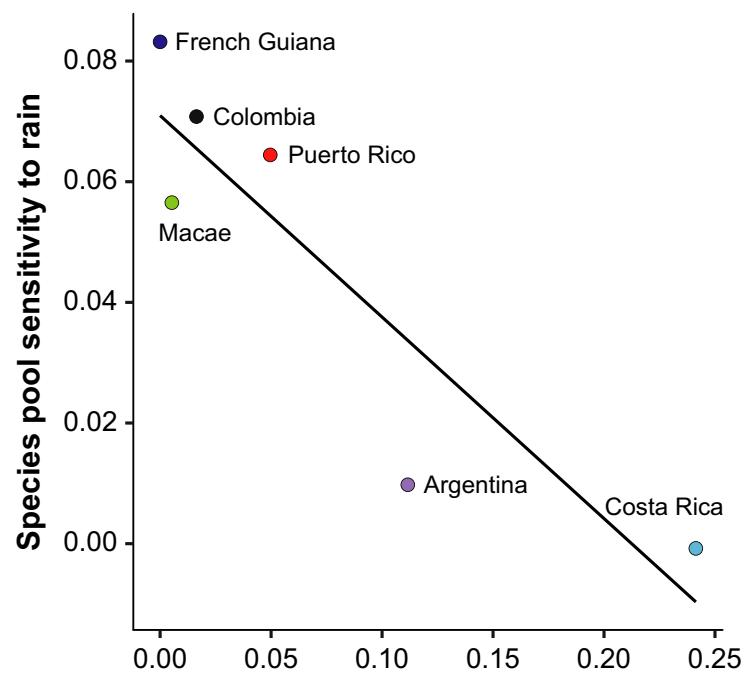

Ambient proportion of days without water

FIG. 3. Sites with bromeliads that rarely dry under ambient conditions have species pools dominated by invertebrate families that are sensitive to rainfall. The sensitivity of each invertebrate family was determined by a global analysis of response to rainfall manipulations. The site of Ilha do Cardoso, Brazil is not represented on this plot as hydrological data was not available for this site.

French Guiana (other sites did not have sufficient piercers for analysis). Overall, piercer biomass was influenced by site-specific effects of hydrology, specifically the frequency of water overflow. However, this pattern was driven entirely by the Macae site in Brazil (Macae, overflow effect on piercer biomass, $\chi_{1}^{2}=8.32, P=0.004$; other sites, $P=0.25-0.36$ ), and could be explained by the sensitivity of Tanypodinae chironomids to overflow events (overflow $\times$ site, $\chi_{1}^{2}=3.9, P=0.048$ ). Indeed, when we captured overflow water, we discovered that $2.1 \pm 0.3$ (mean $\pm \mathrm{SE}$ ) invertebrates are flushed from bromeliads each overflow event, with chironomids among the dominant taxa in flushed water (Appendix S1: Section S5, Appendix S2: Fig. S6). In this case, taxa that were similar in their feeding traits (all piercing predators) differed in the traits that rendered them susceptible to overflow events, creating taxonomic contingency. By contrast, shredder and filter feeder functional groups were both almost entirely composed of one family (Tipulidae and Culicidae, respectively).

So far we have provided evidence that both hydrological and taxonomic mechanisms may underlie site differences in how particular invertebrate functional groups respond to rainfall change. To determine which mechanism is most important overall, we return to multivariate analyses of the relative biomasses of all functional groups, arguably the most integrative measure of the functional capacity of the food web. Sites that differed in how bromeliad hydrology responded to rainfall also differed in how multivariate functional composition responded to rainfall (Fig. 5). By contrast, differences between sites in either species pool composition (Mantel test, $r=-0.39, P=0.96$ ) or hydrologic sensitivity of taxa (Mantel test, $r=-0.25, P=0.82$ ) could not explain site contingency in the response of functional composition to rainfall. Even differences between sites in geographic distance and climatic conditions, variables considered major predictors of biogeographic patterns (Cottenie 2005), could not explain site contingency (Mantel tests, $r<0.08, P>0.332$ ). We add the caveat here that, although hydrological response to rainfall is the strongest correlate of invertebrate responses, this does not preclude the existence of a stronger, untested correlate. Further, our emphasis is on the rank order of correlation coefficients rather than the actual $P$ values, due to the potential for alpha-inflation through multiple comparisons.

\section{Discussion}

\section{System components differ in sensitivity to rainfall and hydrology}

Ecological responses to climatic manipulations have been variously assessed in terms of organismal composition, total stocks of biomass, and ecosystem fluxes. We show here that these responses differ substantially in their sensitivity to rainfall manipulations and associated changes in hydrology, with the strongest effects on invertebrate functional composition.

In this study, we documented shifts in the functional structure of bromeliad invertebrate communities in response to rainfall change. We found that changes in both the mean and dispersion of daily rainfall affected the biomass of invertebrate functional groups, but these groups differed in their sensitivity and response to these two aspects of rainfall. Our results support previous studies of bromeliad invertebrates showing that large alterations in rainfall can shift the relative abundances of functional groups (Dézerald et al. 2015) and disrupt trophic interactions (Pires et al. 2016). In this study, we intentionally categorized species in terms of their functional feeding traits, in order to relate responses to the flow of energy through food webs. The sensitivity of functional feeding groups to rainfall change will depend on how strongly feeding traits covary with resistance and resilience traits (Suding et al. 2008). In general, bromeliad invertebrates occupy a nonrandom subset of trait space, leading to associations between trophic and nontrophic traits axes (Céréghino et al. 2018). Drought therefore results in shifts in the relative abundances of multiple associated traits, including feeding traits, in this system (Dézerald et al. 2015).

It is notable that rainfall change was able to induce change in invertebrate functional composition in our study, even in sites whose species pools contained a limited number of drought-sensitive taxa. Specifically, the hydrologic sensitivity of the species pool, although 

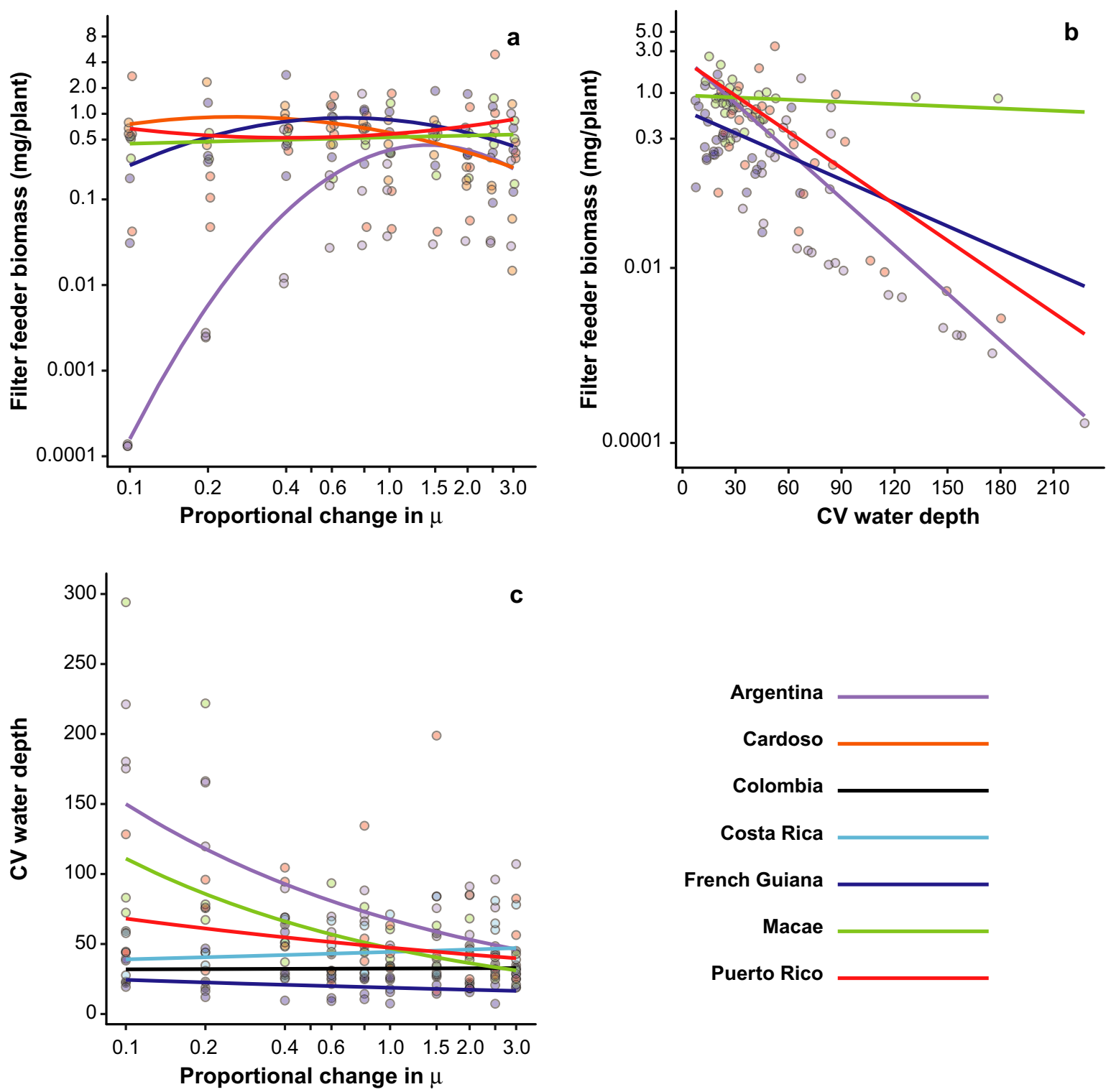

FIG. 4. The biomass of filter-feeding invertebrates in bromeliads shows (a) site-specific responses to change in mean daily rainfall, $\mu$, but (b) generally more consistent responses to the coefficient of variation in bromeliad water depth (CV water depth; site differences are driven by just two bromeliads in Macae, Brazil). (c) Sites differ in the strength of rainfall manipulations on the coefficient of variation water depth. The site of Ilha do Cardoso, Brazil is not represented in panels b and c, as hydrological data were not available for this site. To facilitate interpretation, labels on all axes represent untransformed values of variables but axes (apart from $\mathrm{CV}$ water depth) are on a logarithmic scale to be consistent with model structure.

correlated with ambient drought levels, was not a good predictor of site differences in the strength of rainfall effects on functional composition. We hypothesize that site differences in the hydrologic sensitivity of their species pools reflects filtering by current and/or past drought events. These results contrast with the response of temperate and arid plant communities to multi-site manipulations of precipitation; in both instances, the plants were surprisingly insensitive to precipitation manipulations, a result attributed to adaptation of species pools to historical extremes (Tielbörger et al. 2014, Kröel-Dulay et al. 2015).

Total stocks of bacteria or invertebrates were at most weakly affected by rainfall. This contrasts with the stronger effects of rainfall on individual functional groups of invertebrates. Biological stocks may show muted responses to climatic change due to portfolio effects, where variation in different components is 


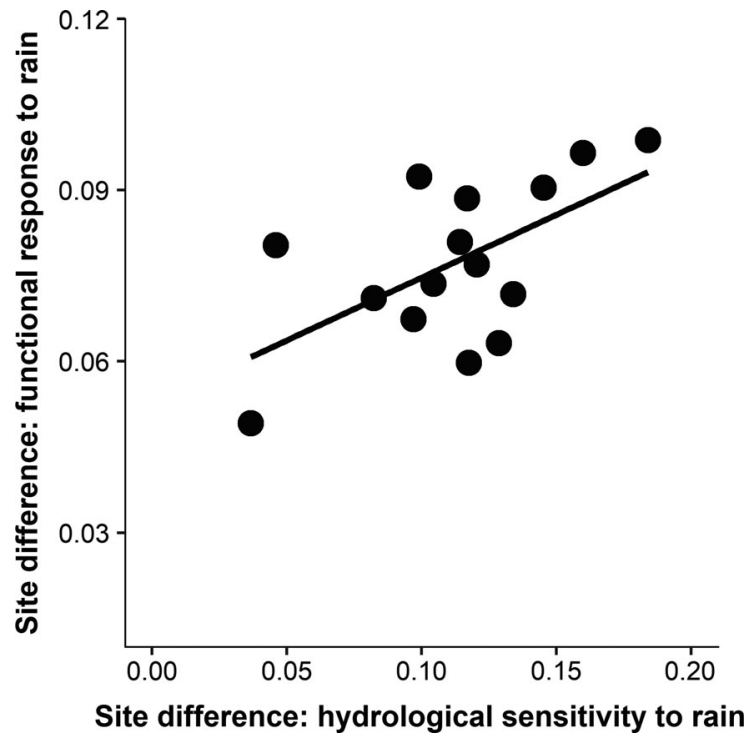

FIG. 5. Sites that differ the most in how functional group composition of invertebrates responds to rainfall change also differ the most in their hydrological sensitivity to rainfall change. Each point on this Mantel correlation $(r=0.58$, $P=0.03$ ) plot represents a different pairwise combination of sites. Site differences were calculated as the effect size of the site $\times$ rainfall interaction term in two-site multivariate models explaining either invertebrate functional group composition (vertical axis) or hydrological variables (horizontal axis).

reduced in their aggregated sum (Doak et al. 1998). In our study, total invertebrate biomass showed no overall response to rainfall change, even though it was composed of functional groups that largely did respond to rainfall, because aggregating the uncorrelated responses of functional groups resulted in a reduced net response. The documentation of portfolio effects in this study cautions that reliance only on the response of aggregate measures of biomass to abiotic change can overlook important shifts in the functional structure of food webs.

Similarly, measures of carbon flux, such as $\mathrm{CO}_{2}$ production and detrital decomposition, were generally insensitive to rainfall change. In bromeliads, $\mathrm{CO}_{2}$ production at dawn, when the plant is not photosynthesizing, is largely derived from detrital decomposition (Atwood et al. 2014, Hammill et al. 2015). Decomposition in bromeliads has been shown to be insensitive to hydroperiod length (Trzcinski et al. 2016, Pérez et al. 2018, Pires et al. 2018), even though hydroperiod affects the relative importance of different decomposition processes (Pérez et al. 2018). Studies in other freshwater habitats also report litter decomposition to be insensitive to hydroperiod, suggesting that this ecosystem function may generally be resistant to precipitation change (Day 1983, Lockaby et al. 1996). By contrast, nitrogen uptake by bromeliads peaked universally at intermediate rainfall dispersions. This suggests some type of trade-off, perhaps between leaching of litter nutrients into the water column and flushing of nutrients through overflow, but further experiments are needed to determine the mechanism.

The fact that ecosystem components can differ in their sensitivity to environmental change complicates attempts to determine the "safe operating space" for ecosystems (Scheffer et al. 2015, Green et al. 2017). The safe operating space of a system is defined as the range of stress that the system can withstand without showing an abrupt change to an altered state (Rockström et al. 2009). For example, increasing drought in stream systems results in a threshold of rapid change in some functional traits (Aspin et al. 2018). However, if the delimitation of this safe operating space differs between ecosystem components (i.e., functional composition, stocks, and fluxes), it is not clear which response type should take primacy. In the case of the bromeliad system, responses to rainfall were either gradual or null, suggesting a high degree of resistance of this system to even large shifts in rainfall. However, it is not clear if sustained rainfall changes over large spatial and temporal scales (not yet possible to simulate with experiments) would erode the capacity of bromeliad ecosystems to withstand state shifts.

\section{Geographic locations differ in sensitivity to rainfall and hydrology}

Climate change is expected to intensify in the future, with further deviations in mean conditions from current baselines, and increasing frequency of extreme climatic conditions as measured by today's standards. A major challenge for ecology is to forecast how the world's ecosystems will function as a result of such continued alterations in the global climate. In this study, we show that the same ecosystem type responds to the same proportional change in precipitation in very different ways, depending on the site at which the experiment is conducted. This means that the ecological responses to rainfall manipulations at one site, or even seven sites, as in this study, cannot directly be extrapolated to predict the responses at a new site. Careful elucidation of the mechanisms underlying this result shows that site contingency in hydrological responses and species pools mediate ecosystem responses to precipitation change.

Sites cannot stand-in for each other because of strong site contingency in the effects of rainfall change, compounded by nonlinearity in responses. One of the most important reasons for this contingency is difference between sites in how rainfall change is realized in terms of bromeliad hydrology. It is hydrology, rather than rainfall, that determines invertebrate colonization and survival in bromeliads (Amundrud and Srivastava 2015, Marino et al. 2017). In our study, if we directly examine how hydrology affects the relative composition of functional groups, or the biomass of individual functional groups like filter feeders, then site differences diminish and predictability increases. All filter feeders in this study were mosquito larvae, a group known to be among 
the most sensitive of bromeliad invertebrates to drought (Amundrud and Srivastava 2015). Mosquito larvae forage in the water column, and this pelagic habitat may explain their sensitivity to fluctuating water levels. In lakes, increased fluctuations in water levels are also associated with a shift from pelagic to benthic invertebrates (Evtimova and Donohue 2016). Unlike temperature, precipitation is expected to only affect organisms through influences on the abiotic environment as characterized by properties such as soil moisture, stream flow, salinity and habitat volume. The implication is that any attempt to build a general model of how precipitation affects ecosystems has to first account for this spatiallyvariable mediation of the abiotic environment by precipitation.

Sites also differ in their response to rainfall change because of geographic differences in the species composition within functional feeding groups. Such taxonomic contingency happens because taxonomic families that fulfil similar trophic functions in food webs can still differ in the traits that make them sensitive to climate change. For example, geographic differences in the taxonomic composition of piercing predators in our study resulted in differences in the sensitivity of this functional group to overflow. By contrast, two other functional groups, shredders and filter feeders, were composed almost entirely of a single family (Tipulidae and Culicidae, respectively); this taxonomic constancy may explain why shredders responded to rain similarly between sites, and why much of the contingency in filter feeder response to rainfall could be explained by hydrology. In general, shredders have lower diversity in tropical than temperate freshwaters (Boyero et al. 2011), suggesting that this functional group may often show general responses to climate change in the tropics. Finally, differences in the species pool between field sites can also result in differences in the structure of food webs, which can by itself affect responses of bromeliad invertebrates to rainfall (Trzcinski et al. 2016).

\section{Contingency and the ecological forecast horizon}

In summary, we found the strongest effects of rainfall change on invertebrate functional composition, and some of the weakest effects on carbon flux, but even the effects on invertebrate functional composition were not consistent between sites. In particular, hydrology and taxonomy created site contingency to rainfall change. This suggests that careful matching of training and test sites in terms of these two criteria could improve system predictability. In the case of the bromeliad system, this would require many more sites that more finely cover climatic and biogeographic space than possible in the current study. Thus the "ecological forecast horizon" (Petchey et al. 2015) for this system is probably much less than the $600-6,000 \mathrm{~km}$ that separated our field sites. Other systems, such as Arctic vegetation, show more geographic consistency in functional group responses to warming, perhaps because many Arctic plant genera have circumpolar distributions (Walker et al. 2006) or because temperature, unlike precipitation, can directly affect organismal physiology. Geographic contingency is often seen as the "Achilles heel" of climate change biology, as it prevents application of the knowledge gained at one site to other sites (Pilkey and Pilkey-Jarvis 2007, Planque 2016). However, instead of seeing contingency as the enemy of application, progress can be made if we understand what processes underlie this contingency (Evans et al. 2013). In this study, we found that the key processes included the effects of rainfall on system hydrology, the contribution of current and historical climates to species pool composition, and the response of particular invertebrate families to hydrologic change. Only through such detailed dissection of contingency can biologists determine the appropriate stratification for experiments and horizons for forecasts, and begin to predict ecological responses to climate change at global scales.

\section{ACKNOWLEDGMENTS}

We appreciate fieldwork assistance by $\mathrm{T}$. Amundrud, $\mathrm{T}$. Bernabé, P. Corvalan, A. M. Fernandez, G. Klekailo, C. López, J. Macedo, A. Mendonça, G. Migliorini, A. Neutzling, B. Oliveira, S. Talaga, P. Trasmonte, and L. Zornig and logistical support from the Área de Conservación Guanacaste, Costa Rica and Aguas de Manizales S.A., Colombia. Funding: we acknowledge financial support for research provided by the Agence Nationale de la Recherche (ANR) through the Rainwebs project (grant ANR-12BSV7-0022-01) to R. Céréghino, C. Leroy, B. Corbara, J. F. Carrias, and D. S. Srivastava and an Investissement d'Avenir grant (Labex CEBA, ref. ANR-10-LABX-25-01) to R. Céréghino, C. Leroy, and O. Dézerald, by the Agencia Nacional de Promoción Científica y Tecnológica (grant PICT-2010-1614) and Secretaría de Ciencia y Tecnología de la Universidad Nacional de Rosario (grant AGR-139) through grants to I. Barberis and G. Montero, by the Brazilian Council for Research, Development and Innovation $(\mathrm{CNPq})$ for research funds (Pesquisador Visitante Especial, PVE, Research Grant 400454/2014-9) and productivity grants to V. F. Farjalla, by the Natural Sciences and Engineering Research Council of Canada (NSERC) through Discovery and Accelerator grant to D. S. Srivastava, by the São Paulo Research Foundation (FAPESP: grants 2012/51143-3 and BPE Proc. \# 2016/01209-9) and CNPq through research grants to G. Q. Romero, and the Facultad de Ciencias, Universidad de los Andes, Colombia through a grant (2012-1) to F. Ospina-Bautista. This research was further supported by scholarship and fellowship support from the ANR to M. K. Trzcinski, from Consejo Nacional de Investigaciones Científicas y Técnicas (CONICET) to R. Freire, from FAPESP to P. A. P. Antiqueira (Proc. 2014/04603-4), from Coordenação de Aperfeiçoamento de Pessoal de Nível Superior (CAPES) to A. B. A. Campos, J. S. Leal, and N. A. C. Marino (PNPD-CAPES 2013/0877) and P. M. de Omena (PNPD-CAPES 2014/04603-4), an Investissement d'Avenir grant (Labex CEBA, ref. ANR-10LABX-25-01) and a PhD fellowship from the Fond Social Européen to O. Dézerald, from NSERC to A. A. M. MacDonald (CGS-D) and D. S. Srivastava (EWR Steacie Memorial Fellowship), from the University of British Columbia to S. L. Amundrud, and from the Departamento Administrativo de Ciencia, Tecnología e Innovación (COLCIENCIAS) support of F. OspinaBautista (COLCIENCIAS grant 567). Authorship order reflects degree of contribution: D. S. Srivastava, I. M. Barberis, J.-F. 
Carrias, R. Céréghino, B. Corbara, V. F. Farjalla, D. A. Mercado, C. Leroy, G. Q. Romero, N. A. C. Marino, A. A. M. MacDonald, and G. C. O. Piccoli designed the global experiment; A. A. M MacDonald and D. S. Srivastava created rainfall schedules; D. S. Srivastava, I. M. Barberis, F. Ospina-Bautista, R. Céréghino, V. F. Farjalla, E. Hammill, D. A. Mercado, G. Montero, E. Realpe, and G. Q. Romero organized site-level experiments. All authors contributed to either field or lab data collection; D. S. Srivastava, A A. M. MacDonald, and N. A. C. Marino collated the data and prepared figures; and D. S. Srivastava performed statistical analyses. D. S. Srivastava wrote the initial draft of the manuscript with input from M. K. Trzcinski, all authors participated in discussing and editing the manuscript.

\section{Literature Cited}

Amundrud, S. L., and D. S. Srivastava. 2015. Drought sensitivity predicts habitat size sensitivity in an aquatic ecosystem. Ecology 96:1957-1965.

Aspin, T. W. H., K. Khamis, T. J. Matthews, A. M. Milner, M J. O'Callaghan, M. Trimmer, G. Woodward, and M. E. Ledger. 2018. Extreme drought pushes stream invertebrate communities over functional thresholds. Global Change Biology $25: 230-244$.

Atwood, T. B., E. Hammill, D. S. Srivastava, and J. S. Richardson. 2014. Competitive displacement alters top-down effects on carbon dioxide concentrations in a freshwater ecosystem. Oecologia 175:353-361.

Beier, C., et al. 2012. Precipitation manipulation experiments challenges and recommendations for the future. Ecology Letters 15:899-911.

Boeck, H., S. De, J. Vicca, I. Nijs Roy, and A. Milcu. 2015. Global change experiments: challenges and opportunities. BioScience 65:922-931.

Boyero, L., et al. 2011. Global distribution of a key trophic guild contrasts with common latitudinal diversity patterns. Ecology 92:1839-1848.

Brouard, O., A. H. Le Jeune, C. Leroy, R. Céréghino, O. Roux, L. Pelozuelo, A. Dejean, B. Corbara, and J. F. Carrias. 2011. Are algae relevant to the detritus-based food web in tankbromeliads? PLoS ONE 6:1-10.

Céréghino, R., et al. 2018. Constraints on the functional trait space of aquatic invertebrates in bromeliads. Functional Ecology 32:2435-2447.

Chadwick, R., P. Good, G. Martin, and D. P. Rowell. 2016. Large rainfall changes consistently projected over substantial areas of tropical land. Nature Climate Change 6:177-181.

Cottenie, K. 2005. Integrating environmental and spatial processes in ecological community dynamics. Ecology Letters 8:1175-1182.

Day, F. P. 1983. Effects of flooding on leaf litter decomposition in microcosms. Oecologia 56:180-184.

Dézerald, O., R. Céréghino, B. Corbara, A. Dejean, and C. Leroy. 2015. Functional trait responses of aquatic macroinvertebrates to simulated drought in a Neotropical bromeliad ecosystem. Freshwater Biology 60:1917-1929.

Dézerald, O., C. Leroy, B. Corbara, A. Dejean, S. Talaga, and R. Céréghino. 2017. Environmental drivers of invertebrate population dynamics in Neotropical tank bromeliads. Freshwater Biology 62:229-242.

Doak, D. F., D. Bigger, E. K. Harding, M. A. Marvier, R. E. O'Malley, and D. Thomson. 1998. The statistical inevitability of stability-diversity relationships in community ecology. American Naturalist 151:264-276.
Duffy, P. B., P. Brando, G. P. Asner, and C. B. Field. 2015. Projections of future meteorological drought and wet periods in the Amazon. Proceedings of the National Academy of Sciences USA 112:13172-13177.

Evans, M. R., et al. 2013. Predictive systems ecology. Proceedings of the Royal Society B 280:20131452.

Evtimova, V. V., and I. Donohue. 2016. Water-level fluctuations regulate the structure and functioning of natural lakes. Freshwater Biology 61:251-264.

Fraser, L. H., J. Pither, A. Jentsch, M. Sternberg, M. Zobel, D. Askarizadeh, S. Bartha, C. Beierkuhnlein, and J. A. Bennett. 2015. Worldwide evidence of a unimodal relationship between productivity and plant species richness. Science 349:302-306.

Goffredi, S. K., G. E. Jang, W. T. Woodside, and W. Ussler. 2011. Bromeliad catchments as habitats for methanogenesis in tropical rainforest canopies. Frontiers in Microbiology $2: 1-14$.

Green, A. J., et al. 2017. Creating a safe operating space for wetlands in a changing climate. Frontiers in Ecology and the Environment 15:99-107.

Hammill, E., T. B. Atwood, and D. S. Srivastava. 2015. Predation threat alters composition and functioning of bromeliad ecosystems. Ecosystems 18:857-866.

Holdridge, L. R. 1947. Determination of world plant formations from simple climatic data. Science 105:367-8.

Hudson, F.2004. Sample preparation and calculations for dissolved gas analysis in water samples using a GC headspace equilibration technique. Method RSKSOP-175. http://www.e pa.gov/region $1 /$ info/testmethods/pdfs/R

Kayler, Z. E., H. J. De Boeck, S. Fatichi, J. M. Grünzweig, L. Merbold, C. Beier, N. McDowell, and J. S. Dukes. 2015. Experiments to confront the environmental extremes of climate change. Frontiers in Ecology and the Environment 13:219-225.

Knapp, A. K., D. L. Hoover, K. R. Wilcox, M. L. Avolio, S. E. Koerner, K. J. La Pierre, M. E. Loik, Y. Luo, O. E. Sala, and M. D. Smith. 2015. Characterizing differences in precipitation regimes of extreme wet and dry years: Implications for climate change experiments. Global Change Biology 21:2624 2633.

Knapp, A. K., et al. 2017. Pushing precipitation to the extremes in distributed experiments: recommendations for simulating wet and dry years. Global Change Biology 23:1774-1782.

Kröel-Dulay, G., et al. 2015. Increased sensitivity to climate change in disturbed ecosystems. Nature Communications 6:6682.

Lawton, J. 1999. Are there general laws in ecology? Oikos 84:177-192.

LeCraw, R. M., P. Kratina, and D. S. Srivastava. 2014. Food web complexity and stability across habitat connectivity gradients. Oecologia 176:903-915.

Lockaby, B. G., A. L. Murphy, and G. L. Somers. 1996. Hydroperiod influences on nutrient dynamics in decomposing litter of a floodplain forest. Soil Science Society of America Journal 60:1267-1272.

Marino, N. A. C., D. S. Srivastava, A. A. M. MacDonald, J. S. Leal, A. B. A. Campos, and V. F. Farjalla. 2017. Rainfall and hydrological stability alter the impact of top predators on food web structure and function. Global Change Biology 23:673-685.

Monfort, P., and B. Baleux. 1992. Comparison of flow cytometry and epifluorescence microscopy for counting bacteria in aquatic ecosystems. Cytometry 13:188-92.

Mori, S., G. Cremers, C. Gracie, J. de Granville, M. Hoff, and J. Mitchell.1997. Guide to the vascular plants of central French Guiana, Part 1. Pteridophytes, gymnosperms, and 
monocotyledons. The New York Botanical Garden, New York, New York, USA.

Pecl, G., M. B. Araujo, J. D. Bell, J. Blanchard, T. C. Bonebrake, G. T. Pecl, M. B. Araujo, and J. Bell. 2017. Biodiversity redistribution under climate change: impacts on ecosystems and human well-being. Science 355:1-9.

Pérez, H. R., G. Borrel, C. Leroy, J. F. Carrias, B. Corbara, D. S. Srivastava, and R. Céréghino. 2018. Simulated drought regimes reveal community resilience and hydrological thresholds for altered decomposition. Oecologia 187:267-279.

Petchey, O. L., et al. 2015. The ecological forecast horizon, and examples of its uses and determinants. Ecology Letters 18:597-611.

Petermann, J. S., et al. 2015. Dominant predators mediate the impact of habitat size on trophic structure in bromeliad invertebrate communities. Ecology 96:428-439.

Pilkey, O., and L. Pilkey-Jarvis. 2007. Useless arithmetic: why environmental scientists can't predict the future. Columbia University Press, New York, New York, USA.

Pires, A. P. F., N. A. C. Marino, D. S. Srivastava, and V. F. Farjalla. 2016. Predicted rainfall changes disrupt trophic interactions in a tropical aquatic ecosystem. Ecology 97: 2750-2759.

Pires, A. P. F., D. S. Srivastava, N. A. C. Marino, A. A. M. MacDonald, M. P. Figueiredo-Barros, and V. F. Farjalla. 2018. Interactive effects of climate change and biodiversity loss on ecosystem functioning. Ecology 99:1203-1213.

Planque, B. 2016. Projecting the future state of marine ecosystems, "la grande illusion"? ICES Journal of Marine Science 73:204-208

Poff, N. L., J. D. Olden, N. K. M. Vieira, D. S. Finn, M. P. Simmons, and B. C. Kondratieff. 2006. Functional trait niches of North American lotic insects: traits-based ecological applications in light of phylogenetic relationships. Journal of the North American Benthological Society 25:730-755.

Rockström, J., et al. 2009. A safe operating space for humanity. Nature 461:472-475.

Romero, G. Q., G. C. O. Piccoli, P. M. De Omena, and T. Gonçalves-Souza. 2016. Food web structure shaped by habitat size and climate across a latitudinal gradient. Ecology 97:2705-2715.

Scheffer, M., S. Barrett, and S. R. Carpenter. 2015. Creating a safe operating space for iconic ecosystems. Science 347:13171319.
Srivastava, D., and M. Vellend. 2005. Biodiversity-ecosystem function research: Is it relevant to conservation? Annual Review of Ecology, Evolution, and Systematics 36:267-294.

Srivastava, D. S., M. K. Trzcinski, B. A. Richardson, and B. Gilbert. 2008. Why are predators more sensitive to habitat size than their prey? Insights from bromeliad insect food webs. American Naturalist 172:761-771.

Stocker, T. 2014. Climate change 2013: the physical science basis: Working Group I contribution to the Fifth assessment report of the Intergovernmental Panel on Climate. Cambridge University Press, Cambridge, UK.

Suding, K. N., S. Lavorel, F. S. Chapin, J. H. C. Cornelissen, S. Díaz, E. Garnier, D. Goldberg, D. U. Hooper, S. T. Jackson, and M. L. Navas. 2008. Scaling environmental change through the community-level: A trait-based response-and-effect framework for plants. Global Change Biology 14:11251140 .

Thompson, R. M., J. Beardall, J. Beringer, M. Grace, and P. Sardina. 2013. Means and extremes: Building variability into community-level climate change experiments. Ecology Letters 16:799-806.

Tielbörger, K., M. C. Bilton, J. Metz, J. Kigel, C. Holzapfel, E. Lebrija-Trejos, I. Konsens, H. A. Parag, and M. Sternberg. 2014. Middle-Eastern plant communities tolerate 9 years of drought in a multi-site climate manipulation experiment. Nature Communications 5:5102.

Trzcinski, M. K., D. S. Srivastava, B. Corbara, O. Dézerald, C. Leroy, J. F. Carrias, A. Dejean, and R. Céréghino. 2016. The effects of food web structure on ecosystem function exceeds those of precipitation. Journal of Animal Ecology 85:11471160 .

Vasseur, D. A., et al. 2014. Increased temperature variation poses a greater risk to species than climate warming. Proceedings of the Royal Society 281:1-8.

Walker, M. D., et al. 2006. Plant community responses to experimental warming across the tundra biome. Proceedings of the National Academy of Sciences USA 103:1342-1346.

Yachi, S., and M. Loreau. 1999. Biodiversity and ecosystem productivity in a fluctuating environment: The insurance hypothesis. Proceedings of the National Academy of Sciences USA 96:1463-1468.

Zotz, G., and V. Thomas. 1999. How much water is in the tank? Model calculations for two epiphytic bromeliads. Annals of Botany 83:183-192.

\section{SUPPORTING INFORMATION}

Additional supporting information may be found in the online version of this article at http://onlinelibrary.wiley.com/doi/ 10.1002/ecy.2984/suppinfo

\section{Data Availability Statement}

The data that support the findings of this study are available at http://doi.org/10.5281/zenodo.1124951. This data was collated and hydrologic metrics calculated by a $\mathrm{R}$ package available at http://doi.org/10.5281/zenodo.1120418. The $\mathrm{R}$ code used to calculate the precipitation treatments and analyze data are archived at, respectively, http://doi.org/10.5281/zenodo.18548 and http://doi.org/ 10.5281 /zenodo. 1124949 